ORIGINAL ARTICLE

\title{
Mortality among a cohort of garment workers exposed to formaldehyde: an update
}

\author{
L E Pinkerton, M J Hein, L T Stayner
}

Occup Environ Med 2004;61:193-200. doi: 10.1136/oem.2003.007476

See end of article for authors' affiliations

...................

Correspondence to: Dr L E Pinkerton, Epidemiology Section, Industrywide Studies Branch, Division of Surveillance, Hazard Evaluations and Field Studies, The National Institute for Occupational Safety and Health, 4676 Columbia Parkway, R-15, Cincinnati, $\mathrm{OH} 45226$ USA; LPinkerton@cdc.gov

Accepted 6 June 2003

\begin{abstract}
Aims: To evaluate the mortality experience of 11039 workers exposed to formaldehyde for three months or more in three garment plants. The mean time weighted average formaldehyde exposure at the plants in the early 1980s was $0.15 \mathrm{ppm}$ but past exposures may have been substantially higher.

Methods: Vital status was updated through 1998, and life table analyses were conducted.

Results: Mortality from all causes (2206 deaths, standardised mortality ratio (SMR) $0.92,95 \% \mathrm{Cl} 0.88$ to 0.96 ) and all cancers (SMR $0.89,95 \% \mathrm{Cl} 0.82$ to 0.97 ) was less than expected based on US mortality rates. A non-significant increase in mortality from myeloid leukaemia (15 deaths, SMR 1.44, 95\% Cl 0.80 to 2.37) was observed. Mortality from myeloid leukaemia was greatest among workers first exposed in the earliest years when exposures were presumably higher, among workers with 10 or more years of exposure, and among workers with 20 or more years since first exposure. No nasal or nasopharyngeal cancers were observed. Mortality from trachea, bronchus, and lung cancer (147 deaths, SMR 0.98, 95\% $\mathrm{Cl} 0.82$ to 1.15 ) was not increased. Multiple cause mortality from leukaemia was increased almost twofold among workers with both 10 or more years of exposure and 20 years or more since first exposure (15 deaths, SMR 1.92, $95 \% \mathrm{Cl} 1.08$ to 3.17). Multiple cause mortality from myeloid leukaemia among this group of workers was also significantly increased (8 deaths, SMR 2.55, 95\% Cl 1.10 to 5.03).

Conclusions: Results support a possible relation between formaldehyde exposure and myeloid leukaemia mortality. Previous epidemiological studies supporting a relation between formaldehyde exposure and leukaemia mortality have been primarily of formaldehyde exposed professional groups, not formaldehyde exposed industrial workers. Limitations include limited power to detect an excess for rare cancers such as nasal and nasopharyngeal cancers and lack of individual exposure estimates.
\end{abstract}

n 1988, Stayner and colleagues reported the mortality experience of 11030 employees with exposure to formaldehyde in three garment facilities in the USA. ${ }^{1}$ This retrospective cohort mortality study was initiated after Stayner et al observed significant excesses in mortality from cancers of the buccal cavity, biliary passages and liver, and other lymphatic and haematopoietic sites among garment workers exposed to formaldehyde in a separate, but overlapping, proportionate mortality study. ${ }^{2}$ The main finding of the cohort mortality study was an excess in mortality from cancers of the buccal cavity (standardised mortality ratio (SMR) 3.43) based on four observed deaths. Excesses in mortality were also observed for cancers of the connective tissue (SMR 3.64), trachea, bronchus, and lung (SMR 1.14), pharynx (SMR 1.13), bladder (SMR 1.12), leukaemia (SMR 1.14), and other lymphopoietic neoplasms (SMR 1.70). ${ }^{1}$

Concern about the potential carcinogenicity of formaldehyde developed after formaldehyde was shown to cause nasal squamous cell carcinomas in rats. ${ }^{3}$ In 1995, the International Agency for Research on Cancer (IARC) classified formaldehyde as a probable human carcinogen with sufficient evidence in experimental animals and limited evidence in humans for the carcinogenicity of formaldehyde. ${ }^{5}$ The evidence for carcinogenicity in humans was considered strongest for nasopharyngeal cancers. Three meta-analyses have been conducted to evaluate the association between formaldehyde exposure and cancers of the upper respiratory tract and lung with somewhat discrepant results. ${ }^{6-8}$ One meta-analysis also evaluated the association between formaldehyde exposure and other cancers. ${ }^{6}$ Excesses in leukaemia and brain cancer mortality were found among formaldehyde exposed professional groups (for example, pathologists, anatomists, and embalmers), but similar excesses were not found among formaldehyde exposed industrial workers. ${ }^{6}$ Because of continuing concern about the possible human carcinogenicity of formaldehyde, we extended the follow up of the cohort described by Stayner and colleagues. ${ }^{1}$ The present report describes the mortality experience of the cohort through 1998, an additional 16 years of follow up.

\section{METHODS}

\section{Cohort description}

The cohort was assembled from the personnel records obtained from three garment manufacturing facilities, which will be referred to as plants 1,2 , and 3. Plants 1 and 3 were located in Georgia; plant 2 was located in Pennsylvania. These garment facilities produced shirts from fabrics which were treated with formaldehyde resins to impart crease resistance and other desirable properties. The fabrics emitted formaldehyde gas resulting in potential occupational exposures. Employees who had worked at least three months after formaldehyde was first introduced into the production process were included in the cohort. Formaldehyde was first introduced in 1959 at plants 1 and 2, and in 1955 at plant 3. Clerical and administrative employees were not included. We also reviewed documentation and data files from the original study to identify employees who met the original cohort criteria, but had been omitted. The final cohort included

Abbreviations: $\mathrm{Cl}$, confidence interval; LTAS, life table analysis system; MCOD, multiple causes of death; NDI, National Death Index; PYAR, person-years-at-risk; SMR, standardised mortality ratio; STEL, short term exposure limit; TWA, time weighted average 


\section{Main messages}

- An excess in myeloid leukaemia mortality was observed among a cohort of formaldehyde exposed garment workers.

- Mortality from myeloid leukaemia was greatest among workers first exposed in the earliest years when exposures were presumably higher, among workers with 10 or more years of exposure, and among workers with 20 or more years since first exposure.

- The findings for leukaemia mortality are consistent with the findings of several studies of formaldehyde exposed professional groups.

- There was no evidence of an association between formaldehyde exposure and mortality from respiratory cancers.

11098 workers, 11029 of whom were in the original cohort and 69 of whom were added. One individual in the original cohort of 11030 workers was deleted because he worked less than three months after formaldehyde was introduced into the production process. Finally, $59(0.5 \%)$ of the 11098 workers in the final cohort were excluded from the analysis because their date of birth was unknown, resulting in 11039 workers available for analysis.

Data on personal exposure levels of formaldehyde for 549 randomly selected employees in five different departments (cutting, collar, parts, assembly, and packaging) are available for 1981 (plant 1) and 1984 (plants 2 and 3). ${ }^{19}$ Briefly, exposure to formaldehyde was similar across departments and plants; the geometric mean eight hour time weighted average (TWA) exposure to formaldehyde across all departments and plants ranged from 0.09 to $0.20 \mathrm{ppm}$. The overall geometric mean concentration of formaldehyde was $0.15 \mathrm{ppm}$ (geometric standard deviation 1.90). Area monitoring showed that the formaldehyde levels were essentially constant without substantial peaks or intermittent exposures. Additional information on the exposure levels found is available elsewhere. ${ }^{19}$ Information on historical exposure levels to formaldehyde was not available for these plants. However, formaldehyde exposures were believed to have been substantially higher in earlier years because the resin systems used in treating permanent press fabrics had been improved to reduce the amount of formaldehyde in the fabrics. The current Occupational Safety and Health Administration (OSHA) standard for formaldehyde exposure is $2 \mathrm{ppm}$ as a short term exposure limit (STEL) and $0.75 \mathrm{ppm}$ as an eight hour TWA.

\section{Follow up}

The vital status of all persons in the cohort was determined through 31 December 1998. Follow up included inquiry through the Social Security Administration, Internal Revenue Service, US Postal Service, National Death Index (NDI), and state bureaus of motor vehicles. Death certificates were obtained from state vital records offices for some deceased members of the cohort and coded by a trained nosologist according to the revision of the International Classification of Diseases in effect at the time of death. The causes of death for other deceased members of the cohort were obtained from the NDI.

Although vital status was updated for the workers in the cohort, the work histories were not. We assumed that exposure (employment) ceased in 1981 for plants 1 and 2 and in 1983 for plant 3 (that is, when the work histories were obtained for the original study). Hence, duration of employment was underestimated for $1230(11.1 \%)$ of the 11039 cohort members who were actively employed when the work history records were obtained.

\section{Analysis}

The mortality experience of the cohort was analysed with the use of the PC version of the National Institute for Occupational Safety and Health (NIOSH) modified life table analysis system (LTAS) ${ }^{10-12}$ (http://www.cdc.gov/niosh/ tindex.html). Each cohort member accumulated personyears-at-risk (PYAR) for each year of life after the three month eligibility period until the date of death for deceased cohort members, the date last observed for persons lost to follow up, or the ending date of the study (31 December 1998) for cohort members known to be alive. In contrast, PYAR were accrued until the ending date of the study for persons lost to follow up in the original study. Cohort members known to be alive after 1 January 1979 (the date that the NDI began) and not identified as deceased were assumed to be alive as of 31 December 1998. The PYAR were stratified into five year intervals by age and calendar time and were then multiplied by the appropriate US gender, race, and cause specific mortality rates to calculate the expected number of deaths for that stratum. At the time of the study, the NIOSH LTAS only maintained US mortality rates through 1997. In order to calculate expected deaths through 1998, the mortality rates for 1995-97 were used for 1998. The resulting expected numbers were summed across strata to obtain cause specific and total expected number of deaths. The ratio of observed to expected number of deaths was expressed as the standardised mortality ratio (SMR). Ninety five per cent confidence intervals (CI) were computed for the SMRs assuming a Poisson distribution for observed deaths. The mortality analysis was repeated using Georgia or Pennsylvania state mortality rates, as appropriate, to generate expected numbers of death. In addition to analyses of underlying cause of death, all causes listed on the death certificate were analysed using multiple cause mortality methods described by Steenland and colleagues. ${ }^{13}$ Multiple cause analyses are particularly important for diseases that may be prevalent at death but that are not the underlying cause of death. ${ }^{13}$ In analyses using state or multiple cause mortality rates, PYAR started to accumulate on 1 January 1960, when the rates were first available, or completion of the three month eligibility period, whichever was later.

We stratified SMRs by duration of exposure $(<3,3-9,10+$ years $)$, time since first exposure $(<10,10-19,20+$ years $)$, and year of first exposure $(<1963,1963-70,1971+)$. The cut points for time since first exposure and year of first exposure were retained from the original study. For the analyses stratified by duration of exposure (that is, duration of employment after formaldehyde was introduced into the process), the cohort was divided into three groups so that each group had an approximately equal number of expected deaths. Testing for heterogeneity and trend in the SMRs was performed using the methods of Breslow and Day (1987). ${ }^{14}$

A sensitivity analysis was performed by replicating the life table analyses under different assumptions in order to evaluate the impact of underestimating duration of exposure for cohort members who were actively employed when the work history records were obtained. First, workers who were still employed at the time the records were obtained were assumed to have worked until age 65 years, the date last observed, or the date the plant closed, whichever came first. There were a small number of employees who were still employed at the time the records were obtained who were already beyond the age of 65 years. These workers were assumed to have continued working for an additional 2 years 
and 8 months beyond age 65 years since the mean duration of employment beyond age 65 years in this cohort is 2.66 years. A second scenario assumed workers under age 65 who were still employed at the time the records were obtained continued to work until halfway between the date the records were obtained and age 65 , the date last observed, or the date the plant closed, whichever came first. Under the two scenarios described, the exposure duration category remained unchanged for 10735 (97.2\%) of the 11039 workers in the analysis. Of the 1230 cohort members who were still employed when the records were obtained, 915 (74.4\%) had already been employed 10 or more years.

We also calculated age adjusted rate ratios by exposure duration, using the lowest exposure duration category as the reference group, for mortality from selected cancers of a priori interest using Poisson regression.

Based on previous studies, the primary a priori outcomes of interest in this study were cancers of the upper respiratory tract. Leukaemia and brain cancer were also a priori outcomes of interest.

\section{RESULTS}

A total of 11039 workers contributing 339241 person-years were included in the study. Table 1 shows the distribution of the cohort by vital status, sex, race, plant, duration of exposure, time since first exposure, and first year of exposure. The cohort is primarily white $(75.6 \%)$ and female $(81.7 \%)$. Roughly half $(51.2 \%)$ of the workers are from plant 1 . Causes of death were obtained from death certificates or the NDI for 2195 (99.5\%) of 2206 individuals known to be deceased. Deaths with missing causes of death were included in the other and unknown causes category. The duration of exposure of the cohort is relatively short with a median of 3.3 years. Over $40 \%$ of the cohort was first exposed prior to 1963, with a median time since first exposure of 31.7 years.

Table 1 Characteristics of the study population

\begin{tabular}{|c|c|c|}
\hline Excluded from analysis* & 59 & \\
\hline Number of workers & 11039 & (100\%) \\
\hline \multicolumn{3}{|l|}{ Race/sex } \\
\hline White male & 1612 & (14.6\%) \\
\hline Non-white male & 403 & $(3.7 \%)$ \\
\hline White female & 6737 & (61.0\%) \\
\hline Non-white female & 2287 & $(20.7 \%)$ \\
\hline \multicolumn{3}{|c|}{ Vital status (as of $31 / 12 / 1998$ ) } \\
\hline Alive & 8648 & $(78.3 \%)$ \\
\hline Dead & 2206 & $(20.0 \%)$ \\
\hline Unknown & 185 & $(1.7 \%)$ \\
\hline \multicolumn{3}{|l|}{ Plant site } \\
\hline Plant 1 & 5647 & $(51.2 \%)$ \\
\hline Plant 2 & 1851 & (16.8\%) \\
\hline Plant 3 & 3541 & (32.1\%) \\
\hline \multicolumn{3}{|l|}{ Year of birth } \\
\hline Median & \multicolumn{2}{|l|}{1939} \\
\hline Range & \multicolumn{2}{|c|}{$1882-1960$} \\
\hline \multicolumn{3}{|c|}{ Age at first exposure (years) } \\
\hline Median & \multicolumn{2}{|l|}{26.2} \\
\hline Range & \multicolumn{2}{|c|}{$15.2-79.8$} \\
\hline \multicolumn{3}{|l|}{ Year first exposed } \\
\hline Prior to 1963 & 4669 & $(42.3 \%)$ \\
\hline $1963-70$ & 3813 & $(34.5 \%)$ \\
\hline 1971 or later & 2557 & $(23.2 \%)$ \\
\hline \multicolumn{3}{|l|}{ Duration of exposure } \\
\hline$<3$ years & 5291 & $(47.9 \%)$ \\
\hline $3-9$ years & 3142 & $(28.5 \%)$ \\
\hline $10+$ years & 2606 & (23.6\%) \\
\hline \multicolumn{3}{|l|}{ Time since first exposure } \\
\hline$<10$ years & 330 & $(3.0 \%)$ \\
\hline $10-19$ years & 411 & $(3.7 \%)$ \\
\hline $20+$ years & 10298 & (93.3\%) \\
\hline \multicolumn{3}{|c|}{$\begin{array}{l}\text { *Missing date of birth. No assumptions were made when date of birtt } \\
\text { was missing. These workers were included in the original study by } \\
\text { Stayner and colleagues.' }\end{array}$} \\
\hline
\end{tabular}

Table 2 shows the results of the analysis for all underlying causes of death by study period. Some findings for the 195582 study period differ slightly from the results reported by Stayner and colleagues in the original study, primarily because of the differences described previously in the study cohort and method for accruing PYAR for persons lost to follow up. Overall, mortality from all causes (SMR 0.92, 95\% CI 0.88 to 0.96 ) was significantly less than expected. Mortality from all malignant neoplasms was also significantly less than expected (SMR $0.89,95 \%$ CI 0.82 to 0.97 ). Mortality from pharyngeal cancer (three deaths, SMR 0.64, $95 \%$ CI 0.13 to 1.86), laryngeal cancer (three deaths, SMR $0.88,95 \%$ CI 0.18 to 2.59 ), and trachea, bronchus, and lung cancer (SMR 0.98, 95\% CI 0.82 to 1.15 ) was not increased. Two of the three cancers of the pharynx were cancers of the hypopharynx; one was of an unspecified site within the pharynx. No cancers of the nasopharynx (expected (exp) 0.96 ) or nose (exp 0.16) were observed. Mortality from cancers of other parts of the respiratory system, a category that includes nasal cancers, was increased (SMR 1.21, 95\% CI 0.15 to 4.37), based on two cancers of the pleura. No additional deaths from cancer of the buccal cavity were observed in the analyses of underlying cause of death during this update. Mortality from cancer of the buccal cavity (four deaths, SMR 1.33, 95\% CI 0.36 to 3.41 ) was increased, but the observed excess was substantially less than the excess observed in the previous study and not statistically significant. Mortality from brain cancer and leukaemia was similar to that expected, with both SMRs equal to 1.09 (95\% CI 0.66 to 1.71 and 0.70 to 1.62 for brain cancer and leukaemia, respectively). Among outcomes other than those of a priori interest, non-significant excesses were observed for mortality from cancer of the connective and soft tissue (seven deaths, SMR $1.57,95 \%$ CI 0.63 to 3.24 ), prostate cancer (11 deaths, SMR $1.58,95 \%$ CI 0.79 to 2.83 ), and, based on two observed deaths each, other male genital cancer (SMR 3.89, 95\% CI 0.47 to 14.04 ) and thyroid cancer (SMR 1.16, 95\% CI 0.14 to 4.18). Among non-malignant causes of death, mortality from cardiomyopathy, conductive disorders, and other heart diseases (SMR 1.17, 95\% CI 1.00 to 1.36) was increased.

Table 3 shows the results of additional analyses to evaluate mortality from heart disease and leukaemia in more detailed subgroupings. Mortality was significantly increased for other heart disease (SMR 1.43, 95\% CI 1.10 to 1.83 ) and nonsignificantly increased for conductive disorders (SMR 1.32, $95 \%$ CI 0.97 to 1.74 ) and myeloid leukaemia (15 deaths, SMR $1.44,95 \%$ CI 0.80 to 2.37 ). The underlying cause of death for most of the deaths from other heart disease was heart failure. The excess in myeloid leukaemia mortality was due to a nonsignificant increase in both acute myeloid leukaemia (nine deaths, SMR $1.34,95 \%$ CI 0.61 to 2.54 ) and chronic myeloid leukaemia mortality (four deaths, SMR 1.39, 95\% CI 0.38 to 3.56).

In order to evaluate whether regional variations in mortality rates could explain the findings, analyses were also conducted using state rates as the comparison population. Mortality from conductive disorders (SMR 0.72, 95\% CI 0.53 to 0.95 ) and other heart disease (SMR 0.93, 95\% CI 0.71 to 1.19 ) was not increased based on state rates. The results using state rates and US rates were similar for the causes of death of a priori interest (leukaemia, brain, and upper respiratory cancers).

Table 4 shows the results from analysis stratified by duration of exposure and time since first exposure for selected causes of death with five or more observed deaths. Mortality from leukaemia, myeloid leukaemia, and acute myeloid leukaemia was greatest among workers with 10 or more years of exposure and among workers with 20 years or 
Table 2 Garment workers' mortality results (US referent rates); update of cohort to $1998 \dagger$

\begin{tabular}{|c|c|c|c|c|c|c|c|c|c|}
\hline \multirow{2}{*}{$\begin{array}{l}\text { Underlying cause of death } \\
\text { (ICD codes) } \ddagger\end{array}$} & \multicolumn{3}{|c|}{ Original study period (1955-82) } & \multicolumn{3}{|c|}{ Updated period (1983-98) } & \multicolumn{3}{|c|}{ Total study period (1955-98) } \\
\hline & OBS & SMR & $95 \% \mathrm{Cl}$ & OBS & SMR & $95 \% \mathrm{Cl}$ & OBS & SMR & $95 \% \mathrm{Cl}$ \\
\hline All deaths & 635 & $0.80^{* *}$ & 0.74 to 0.86 & 1571 & 0.98 & 0.93 to 1.03 & 2206 & $0.92^{* *}$ & 0.88 to 0.96 \\
\hline All cancers (140-208) & 193 & $0.86^{*}$ & 0.74 to 0.98 & 415 & 0.91 & 0.83 to 1.00 & 608 & $0.89^{* *}$ & 0.82 to 0.97 \\
\hline Buccal and pharyngeal CA (140-149) & 6 & 1.58 & 0.58 to 3.45 & 2 & 0.31 & 0.04 to 1.14 & 8 & 0.79 & 0.34 to 1.55 \\
\hline Buccal cavity (142-145) & 4 & 3.53 & 0.96 to 9.02 & 0 & 0.00 & 0.00 to 1.98 & 4 & 1.33 & 0.36 to 3.41 \\
\hline Pharynx (146-149) & 2 & 1.15 & 0.14 to 4.15 & 1 & 0.34 & 0.01 to 1.87 & 3 & 0.64 & 0.13 to 1.86 \\
\hline All digestive CA (150-159) & 34 & $0.68^{*}$ & 0.47 to 0.95 & 82 & 0.81 & 0.65 to 1.01 & 116 & $0.77^{\star \star}$ & 0.63 to 0.92 \\
\hline Oesophagus (150) & 2 & 0.78 & 0.09 to 2.82 & 4 & 0.63 & 0.17 to 1.62 & 6 & 0.68 & 0.25 to 1.47 \\
\hline Stomach (151) & 4 & 0.63 & 0.17 to 1.61 & 9 & 0.91 & 0.41 to 1.72 & 13 & 0.80 & 0.42 to 1.36 \\
\hline Colon (152-153) & 18 & 0.85 & 0.50 to 1.34 & 31 & 0.74 & 0.50 to 1.05 & 49 & 0.77 & 0.57 to 1.02 \\
\hline Rectal (154) & 1 & 0.21 & 0.01 to 1.19 & 6 & 0.89 & 0.32 to 1.93 & 7 & 0.61 & 0.25 to 1.26 \\
\hline Liver and biliary (155-156) & 3 & 0.59 & 0.12 to 1.74 & 11 & 0.99 & 0.49 to 1.77 & 14 & 0.87 & 0.47 to 1.45 \\
\hline Pancreas (157) & 6 & 0.64 & 0.23 to 1.39 & 20 & 0.87 & 0.53 to 1.35 & 26 & 0.81 & 0.53 to 1.18 \\
\hline All respiratory CA (160-165) & 39 & 1.03 & 0.73 to 1.41 & 113 & 0.96 & 0.79 to 1.15 & 152 & 0.98 & 0.83 to 1.14 \\
\hline Larynx (161) & 0 & 0.00 & 0.00 to 3.39 & 3 & 1.30 & 0.27 to 3.81 & 3 & 0.88 & 0.18 to 2.59 \\
\hline Trachea, bronchus, and lung (162) & 39 & 1.08 & 0.77 to 1.48 & 108 & 0.94 & 0.77 to 1.14 & 147 & 0.98 & 0.82 to 1.15 \\
\hline Other respiratory $(160,163-165)$ & 0 & 0.00 & 0.00 to 5.63 & 2 & 2.01 & 0.24 to 7.25 & 2 & 1.21 & 0.15 to 4.37 \\
\hline Breast CA (174-175) & 33 & $0.70^{*}$ & 0.48 to 0.98 & 68 & 0.92 & 0.71 to 1.16 & 101 & 0.83 & 0.68 to 1.01 \\
\hline Female genital CA (179-184) & 25 & 0.80 & 0.52 to 1.18 & 31 & 0.75 & 0.51 to 1.07 & 56 & 0.77 & 0.58 to 1.01 \\
\hline Male genital CA (185-187) & 1 & 0.48 & 0.01 to 2.68 & 12 & $2.22^{*}$ & 1.15 to 3.89 & 13 & 1.74 & 0.93 to 2.98 \\
\hline Prostate CA (185) & 0 & 0.00 & 0.00 to 2.15 & 11 & $2.10^{*}$ & 1.05 to 3.76 & 11 & 1.58 & 0.79 to 2.83 \\
\hline Other male genital CA (186-187) & 1 & 2.79 & 0.07 to 15.51 & 1 & 6.41 & 0.16 to 35.59 & 2 & 3.89 & 0.47 to 14.04 \\
\hline All urinary CA (188-189) & 5 & 0.83 & 0.27 to 1.94 & 7 & 0.49 & 0.20 to 1.01 & 12 & 0.59 & 0.30 to 1.03 \\
\hline Kidney (189.0-189.2) & 2 & 0.57 & 0.07 to 2.04 & 3 & 0.36 & 0.07 to 1.06 & 5 & $0.42^{*}$ & 0.14 to 0.99 \\
\hline Bladder and other $(188,189.3-189.9)$ & 3 & 1.20 & 0.25 to 3.51 & 4 & 0.66 & 0.18 to 1.69 & 7 & 0.82 & 0.33 to 1.69 \\
\hline \multicolumn{10}{|l|}{ All other and unspecified site CA } \\
\hline$(170-173,190-199)$ & 30 & 1.10 & 0.74 to 1.57 & 61 & 1.13 & 0.87 to 1.46 & 91 & 1.12 & 0.90 to 1.38 \\
\hline Brain CA $(191,192)$ & 5 & 0.72 & 0.23 to 1.69 & 14 & 1.34 & 0.73 to 2.24 & 19 & 1.09 & 0.66 to 1.71 \\
\hline Thyroid CA (193) & 1 & 1.56 & 0.04 to 8.67 & 1 & 0.92 & 0.02 to 5.11 & 2 & 1.16 & 0.14 to 4.18 \\
\hline Connective and soft tissue (171) & 4 & 3.14 & 0.86 to 8.03 & 3 & 0.94 & 0.19 to 2.76 & 7 & 1.57 & 0.63 to 3.24 \\
\hline Other/unspecified site CA (194-199) & 18 & 1.32 & 0.78 to 2.09 & 36 & 1.13 & 0.79 to 1.57 & 54 & 1.19 & 0.89 to 1.55 \\
\hline \multicolumn{10}{|l|}{ All lymphatic and haematopoietic CA } \\
\hline$(200-208)$ & 20 & 1.01 & 0.62 to 1.56 & 39 & 0.96 & 0.68 to 1.31 & 59 & 0.97 & 0.74 to 1.26 \\
\hline Lymphosarcoma and reticulosarcoma & & & & & & & & & \\
\hline (200) & 2 & 0.50 & 0.06 to 1.79 & 3 & 1.63 & 0.34 to 4.78 & 5 & 0.85 & 0.28 to 1.99 \\
\hline Hodgkin's disease (201) & 1 & 0.41 & 0.01 to 2.30 & 1 & 0.81 & 0.02 to 4.51 & 2 & 0.55 & 0.07 to 1.98 \\
\hline Leukaemia (204-208) & 9 & 1.14 & 0.52 to 2.17 & 15 & 1.05 & 0.59 to 1.74 & 24 & 1.09 & 0.70 to 1.62 \\
\hline \multicolumn{10}{|l|}{ Other lymphatic and haematopoietic } \\
\hline CA (202-203) & 8 & 1.46 & 0.63 to 2.87 & 20 & 0.85 & 0.52 to 1.32 & 28 & 0.97 & 0.64 to 1.40 \\
\hline Benign and unspecified neoplasms & & & & & & & & & \\
\hline$(210-239)$ & 4 & 1.00 & 0.27 to 2.56 & 6 & 1.02 & 0.37 to 2.22 & 10 & 1.01 & 0.48 to 1.86 \\
\hline Tuberculosis (010-018) & 1 & 0.45 & 0.01 to 2.49 & 2 & 1.60 & 0.19 to 5.77 & 3 & 0.86 & 0.18 to 2.52 \\
\hline Diabetes mellitus (250) & 4 & $0.23^{* *}$ & 0.06 to 0.60 & 29 & $0.65^{*}$ & 0.43 to 0.93 & 33 & $0.53^{* *}$ & 0.37 to 0.75 \\
\hline Diseases of the blood (280-289) & 1 & 0.30 & 0.01 to 1.69 & 9 & 1.29 & 0.59 to 2.45 & 10 & 0.98 & 0.47 to 1.79 \\
\hline Mental disorders $(290-319)$ & 1 & $0.17^{*}$ & 0.00 to 0.97 & 23 & 1.08 & 0.68 to 1.61 & 24 & 0.89 & 0.57 to 1.32 \\
\hline Non-malignant nervous system disease & & & & & & & & & \\
\hline$(320-389)$ & 3 & $0.27^{*}$ & 0.06 to 0.80 & 27 & 0.85 & 0.56 to 1.24 & 30 & 0.71 & 0.48 to 1.01 \\
\hline Heart disease $(390-398,402,404$, & & & & & & & & & \\
\hline $410-414,420-429)$ & 179 & $0.81^{* *}$ & 0.69 to 0.93 & 513 & 1.04 & 0.95 to 1.13 & 692 & 0.96 & 0.89 to 1.04 \\
\hline Ischaemic heart disease (410-414) & 145 & $0.83^{*}$ & 0.70 to 0.98 & 333 & 1.01 & 0.90 to 1.12 & 478 & 0.95 & 0.86 to 1.03 \\
\hline $\begin{array}{l}\text { Cardiomyopathy, conductive } \\
\text { disorders, and other heart diseases }\end{array}$ & & & & & & & & & \\
\hline$(420-423,425-428,429.2-429.9)$ & 25 & 1.03 & 0.67 to 1.53 & 150 & $1.19^{*}$ & 1.01 to 1.40 & 175 & $1.17^{*}$ & 1.00 to 1.36 \\
\hline Other circulatory disease $(401,403,405$, & & & & & & & & & \\
\hline $415-417,430-459)$ & 61 & 0.79 & 0.60 to 1.01 & 167 & 1.02 & 0.87 to 1.19 & 228 & 0.95 & 0.83 to 1.08 \\
\hline Non-malignant respiratory disease & & & & & & & & & \\
\hline$(460-519)$ & 28 & 0.75 & 0.50 to 1.08 & 148 & 1.09 & 0.92 to 1.28 & 176 & 1.01 & 0.87 to 1.18 \\
\hline Chronic and unspecified bronchitis & & & & & & & & & \\
\hline$(490-491)$ & 4 & 2.51 & 0.68 to 6.43 & 2 & 0.76 & 0.09 to 2.76 & 6 & 1.42 & 0.52 to 3.10 \\
\hline Emphysema (492) & 8 & 1.50 & 0.65 to 2.96 & 12 & 0.94 & 0.49 to 1.65 & 20 & 1.11 & 0.68 to 1.71 \\
\hline Asthma (493) & 0 & 0.00 & 0.00 to 1.55 & 8 & 1.50 & 0.65 to 2.96 & 8 & 1.04 & 0.45 to 2.05 \\
\hline Pneumoconiosis and other respiratory & & & & & & & & & \\
\hline disease $(470-478,494-519)$ & 5 & $0.42^{*}$ & 0.14 to 0.98 & 88 & $1.29^{*}$ & 1.03 to 1.58 & 93 & 1.16 & 0.93 to 1.42 \\
\hline Non-malignant digestive disease & & & & & & & & & \\
\hline$(520-579)$ & 32 & 0.71 & 0.49 to 1.00 & 51 & 0.79 & 0.59 to 1.04 & 83 & $0.76^{*}$ & 0.60 to 0.94 \\
\hline Cirrhosis of the liver (571) & 18 & 0.73 & 0.44 to 1.16 & 13 & $0.53^{*}$ & 0.28 to 0.90 & 31 & $0.63^{* *}$ & 0.43 to 0.89 \\
\hline Non-malignant genitourinary disease & & & & & & & & & \\
\hline$(580-629)$ & 12 & 1.02 & 0.53 to 1.78 & 33 & 1.17 & 0.80 to 1.64 & 45 & 1.12 & 0.82 to 1.50 \\
\hline Acute renal failure $(580,581,584)$ & 2 & 2.32 & 0.28 to 8.37 & 5 & 1.95 & 0.63 to 4.57 & 7 & 2.05 & 0.82 to 4.22 \\
\hline Chronic renal failure $(582,583$, & & & & & & & & & \\
\hline $585-587)$ & 1 & 0.21 & 0.01 to 1.19 & 16 & 1.24 & 0.71 to 2.01 & 17 & 0.97 & 0.56 to 1.55 \\
\hline Non-malignant skin disease (680-709) & 1 & 0.80 & 0.02 to 4.47 & 3 & 1.32 & 0.27 to 3.85 & 4 & 1.14 & 0.31 to 2.90 \\
\hline Non-malignant musculoskeletal disease & & & & & & & & & \\
\hline (710-739) & 3 & 0.74 & 0.15 to 2.18 & 9 & 1.00 & 0.46 to 1.91 & 12 & 0.92 & 0.48 to 1.61 \\
\hline $\begin{array}{l}\text { Ill defined conditions (780-796, } \\
\text { 798-799) }\end{array}$ & 5 & 0.45 & 0.15 to 1.05 & 8 & 0.56 & 0.24 to 1.10 & 13 & $0.51^{*}$ & 0.27 to 0.88 \\
\hline
\end{tabular}


Table 2 continued

\begin{tabular}{|c|c|c|c|c|c|c|c|c|c|}
\hline \multirow{2}{*}{$\begin{array}{l}\text { Underlying cause of death } \\
\text { (ICD codes) } \ddagger\end{array}$} & \multicolumn{3}{|c|}{ Original study period (1955-82) } & \multicolumn{3}{|c|}{ Updated period (1983-98) } & \multicolumn{3}{|c|}{ Total study period (1955-98) } \\
\hline & OBS & SMR & $95 \% \mathrm{Cl}$ & OBS & SMR & $95 \% \mathrm{Cl}$ & OBS & SMR & $95 \% \mathrm{Cl}$ \\
\hline Accidents (E800-E949) & 52 & 0.89 & 0.67 to 1.17 & 48 & 1.02 & 0.75 to 1.36 & 100 & 0.95 & 0.77 to 1.16 \\
\hline Violence (E950-E978) & 35 & 0.95 & 0.66 to 1.32 & 28 & 1.13 & 0.75 to 1.63 & 63 & 1.02 & 0.78 to 1.31 \\
\hline Other and unknown causes $\S$ & 20 & 1.05 & 0.64 to 1.63 & 52 & 0.94 & 0.70 to 1.23 & 72 & 0.97 & 0.76 to 1.22 \\
\hline
\end{tabular}

OBS, observed number of deaths; SMR, standardised mortality ratio; $\mathrm{Cl}$, confidence interval; $\mathrm{CA}$, cancer.

†Results for all race/sex groups combined.

†International Classification of Diseases, 9th revision.

$\S$ Includes 11 observed deaths in total study period with missing death certificates.

*95\% Cl excludes the null value (1.0).

**99\% Cl excludes the null value (1.0).

more since first exposure. The SMR for myeloid leukaemia among workers with both 10 or more years of exposure and 20 years or more since first exposure was 2.43 (seven deaths, 95\% CI 0.98 to 5.01). Mortality from acute myeloid leukaemia among this group of workers was similarly increased (five deaths, SMR 2.51, 95\% CI 0.81 to 5.85). Mortality from cancer of the trachea, bronchus, and lung was inversely related to duration of exposure and highest among workers with less than 10 years since first exposure. There was no clear pattern between mortality from prostatic cancer and duration of exposure. Mortality from brain cancer, connective tissue cancer, and cardiomyopathy, conductive disorders, and other heart diseases was highest among workers with less than three years of exposure.

The results stratified by duration of exposure were essentially unchanged when the analyses were repeated under different assumptions about the duration of exposure for workers who were actively employed when the work history records were obtained. The SMR for myeloid leukaemia among workers exposed for 3-9 years increased from 1.26 to 1.30 under the scenarios in which individuals who were still employed when the work history records were obtained were assumed to have continued working; the SMR among workers exposed 10 or more years decreased from 2.19 to 2.13. Similar patterns were observed across exposure duration categories in the internal analysis for lung cancer, leukaemia, and brain cancer. For example, the age adjusted rate ratio for leukaemia among those exposed 3-9 years and 10 or more years was 0.67 (95\% CI 0.21 to 2.17 ) and 1.25 (95\% CI 0.46 to 3.43 ), respectively, compared to workers exposed for less than three years.

Table 5 shows the results from analyses stratified by year of first exposure. Mortality from brain cancer, leukaemia, and myeloid leukaemia was highest among workers first exposed prior to 1963, when exposures to formaldehyde were presumably higher. Mortality from prostate cancer and cancer of the trachea, bronchus, and lung was highest among workers first exposed in 1971 or later.

Finally, one additional cancer of the buccal cavity was detected in the multiple causes of death (MCOD) analysis (five deaths, SMR 1.37, 95\% CI 0.44 to 3.21). Seven additional leukaemia deaths (SMR 1.19, 95\% CI 0.81 to 1.68), including two additional myeloid leukaemia deaths (SMR 1.38, 95\% CI 0.80 to 2.20 ) and five additional lymphocytic leukaemia deaths (SMR 1.11, 95\% CI 0.48 to 2.19) were observed in the MCOD analysis. Among workers with 10 or more years of exposure, multiple cause mortality was significantly increased for leukaemia (17 deaths, SMR $1.78,95 \%$ CI 1.04 to 2.86 ) and myeloid leukaemia (nine deaths, SMR 2.24, 95\% CI 1.02 to 4.25 ) and non-signficantly increased for lymphocytic leukaemia (six deaths, SMR 2.12, $95 \%$ CI 0.78 to 4.62 ). The excess in leukaemia (26 deaths, SMR $1.48,95 \%$ CI 0.97 to 2.17 ) and myeloid leukaemia (15 deaths, SMR 2.02, 95\% CI 1.13 to 3.34) mortality, based on MCOD, was concentrated among workers with 20 or more years since first exposure. All lymphocytic leukaemia deaths occurred among workers with 10 or more years since first exposure (10-19 years since first exposure: two deaths, SMR $1.75,95 \%$ CI 0.21 to $6.31 ; 20$ or more years since first

Table 3 Garment workers' mortality (since 1960†) from leukaemia and heart disease (US referent rates): update of cohort to 1998

\begin{tabular}{|c|c|c|c|}
\hline Cause of death (ICD codes) $\S$ & OBS & SMR & $95 \% \mathrm{Cl}$ \\
\hline Leukaemia (204-208) & 24 & 1.09 & 0.70 to 1.63 \\
\hline Lymphocytic leukaemia (204) & 3 & 0.60 & 0.12 to 1.75 \\
\hline Myeloid leukaemia (205) & 15 & 1.44 & 0.80 to 2.37 \\
\hline Acute myeloid leukaemia (205.0) & 9 & 1.34 & 0.61 to 2.54 \\
\hline Chronic myeloid leukaemia (205.1) & 4 & 1.39 & 0.38 to 3.56 \\
\hline Other and unspecified myeloid leukaemia (205.2-205.9) & 1 & 2.15 & 0.05 to 11.94 \\
\hline Other and unspecified leukaemia (206-208) & 6 & 0.92 & 0.34 to 2.00 \\
\hline Heart disease $(390-398,402-404,410-414,420-429)$ & 691 & 0.97 & 0.90 to 1.04 \\
\hline Ischaemic heart disease $(410-414,429.2)$ & 522 & 0.94 & 0.86 to 1.03 \\
\hline Cardiomyopathy (425) & 19 & 0.99 & 0.59 to 1.54 \\
\hline Conductive disorders (426-427) & 49 & 1.32 & 0.97 to 1.74 \\
\hline Other heart diseases $(420-423,428,429.3-429.9)$ & 62 & $1.43^{\star *}$ & 1.10 to 1.83 \\
\hline \multicolumn{4}{|c|}{$\begin{array}{l}\text { OBS, observed number of deaths; SMR, standardised mortality ratio; } \mathrm{Cl} \text {, confidence interval; } \mathrm{CA}=\text { cancer. } \\
\text { †Results for subtypes of myeloid leukaemia are for 1968, when US mortality rates for acute myeloid leukaemia an } \\
\text { chronic myeloid leukaemia were first available, through 1998. One chronic myeloid leukaemia death occurred } \\
\text { prior to } 1968 \text {. } \\
\text { †Results for all race/sex groups combined. } \\
\text { §lnternational Classification of Diseases, } 9 \text { th revision. } \\
\text { *95\% Cl excludes the null value (1.0). } \\
* * 99 \% \mathrm{Cl} \text { excludes the null value (1.0). }\end{array}$} \\
\hline
\end{tabular}


Table 4 Garment workers' mortality (since 1955†) from selected causes of death by duration of exposure and time since first exposure (US referent rates); update of cohort to 1998¥

\begin{tabular}{|c|c|c|c|c|c|c|}
\hline \multirow[b]{2}{*}{ Cause of death (ICD codes)§ } & \multicolumn{3}{|c|}{ Duration of exposure } & \multicolumn{3}{|c|}{ Time since first exposure } \\
\hline & $\begin{array}{l}<3 \text { years } \\
\text { SMR (OBS) }\end{array}$ & $\begin{array}{l}\text { 3-9 years } \\
\text { SMR (OBS) }\end{array}$ & $\begin{array}{l}\text { 10+ years } \\
\text { SMR (OBS) }\end{array}$ & $\begin{array}{l}<10 \text { years } \\
\text { SMR (OBS) }\end{array}$ & $\begin{array}{l}10-19 \text { years } \\
\text { SMR (OBS) }\end{array}$ & $\begin{array}{l}20+\text { years } \\
\text { SMR (OBS) }\end{array}$ \\
\hline All deaths & $1.03(754)$ & $0.89(689)^{* *}$ & $0.85(763)^{* *}$ & $0.79(216)^{* *}$ & $0.78(379)^{* *}$ & $0.98(1611)$ \\
\hline All cancers (140-208) & $1.04(221)$ & $0.85(180)^{*}$ & $0.81(207)^{* * \star}$ & $0.84(56)$ & $0.80(115)^{*}$ & $0.93(437)$ \\
\hline Trachea, bronchus, and lung CA (162) & $1.26(61)$ & $1.07(47)$ & $0.67(39)^{* *}$ & $1.77(14)$ & $0.97(25)$ & $0.92(108)$ \\
\hline Prostate CA (185) & $1.83(4)$ & $0.43(1)$ & $2.46(6)$ & $-(0)$ & $0.70(1)$ & $1.99(10)$ \\
\hline Brain CA $(191,192)$ & $1.45(9)$ & $0.94(5)$ & $0.86(5)$ & $0.82(2)$ & 0.97 (4) & 1.20 (13) \\
\hline Connective and soft tissue CA (171) & $2.42(4)$ & $2.26(3)$ & $-(0)$ & $2.30(1)$ & $2.15(2)$ & $1.30(4)$ \\
\hline Leukaemia (204-208) & $0.96(7)$ & $0.72(5)$ & $1.53(12)$ & $0.68(2)$ & $0.65(3)$ & $1.31(19)$ \\
\hline Myeloid leukaemia (205) & $0.83(3)$ & $1.26(4)$ & $2.19(8)$ & $0.90(1)$ & $0.40(1)$ & $1.91(13)^{*}$ \\
\hline Acute myeloid leukaemia (205.0) & $0.44(1)$ & $1.53(3)$ & $2.02(5)$ & $-(0)$ & $-(0)$ & $1.93(9)$ \\
\hline $\begin{array}{l}\text { Heart disease (390-398, 402, 404, } \\
410-414,420-429)\end{array}$ & $1.15(210)$ & $0.93(225)$ & $0.88(257)^{*}$ & $0.80(48)$ & $0.88(117)$ & $1.00(527)$ \\
\hline Ischaemic heart disease (410-414) & $1.11(139)$ & $0.93(161)$ & $0.86(178)^{*}$ & $0.92(40)$ & $0.92(94)$ & $0.96(344)$ \\
\hline $\begin{array}{l}\text { Cardiomyopathy, conductive } \\
\text { disorders, and other heart diseases } \\
(420-423,425-428,429.2-429.9)\end{array}$ & $1.45(58)^{* *}$ & $1.01(48)$ & $1.10(69)$ & $0.90(5)$ & $0.94(17)$ & $1.21(153)^{*}$ \\
\hline
\end{tabular}

OBS, observed number of deaths; SMR, standardised mortality ratio; $C A$, cancer

†Results for myeloid leukaemia and acute myeloid leukaemia are for 1960 and 1968, respectively, when US population rates for myeloid leukaemia and acute myeloid leukaemia were first available, through 1998.

$\ddagger$ Results for all race/sex groups combined.

§International Classification of Diseases, 9th revision.

*95\% Cl excludes the null value (1.0).

$* * 99 \% \mathrm{Cl}$ excludes the null value (1.0)

१Test for trend, $\mathrm{p}<0.05$.

exposure: six deaths, SMR 1.14, 95\% CI 0.42 to 2.48). Among workers with both 10 or more years of exposure and 20 years or more since first exposure, multiple cause mortality from leukaemia was significantly increased almost twofold (15 deaths, SMR 1.92, 95\% CI 1.08 to 3.17). Multiple cause mortality from myeloid leukaemia was also significantly increased among this group of workers (eight deaths, SMR $2.55,95 \%$ CI 1.10 to 5.03). Multiple cause analyses were also conducted for acute myeloid leukaemia beginning in 1968, when US multiple cause mortality rates for acute myeloid leukaemia were first available. The multiple cause SMR for acute myeloid leukaemia was 1.25 (nine deaths, 95\% CI 0.57 to 2.37) among the entire cohort, 1.91 (five deaths, 95\% CI 0.62 to 4.45 ) among workers with 10 or more years of exposure, and 1.84 (nine deaths, $95 \%$ CI 0.84 to 3.49 ) among workers with 20 or more years since first exposure. No cancers of the nasal cavities or nasopharynx were identified in the MCOD analysis.

\section{DISCUSSION}

We observed a small increase in mortality from leukaemia among a cohort of formaldehyde exposed garment workers. This excess was primarily driven by a moderate increase in myeloid leukaemia mortality. There was also a non-significant increase in lymphocytic leukaemia mortality, based on MCOD, especially among workers with 10 or more years of exposure. Lymphocytic leukaemia mortality was not increased in the underlying cause of death analysis, but in the USA, the five year survival rate for chronic lymphocytic leukaemia, which is more common than acute lymphocytic

Table 5 Garment workers' mortality (since 1955†) from selected causes by year of first exposure (US referent rates); update of cohort to 1998 ‡

\begin{tabular}{|c|c|c|c|}
\hline \multirow[b]{2}{*}{ Cause of death (ICD codes)§ } & \multicolumn{3}{|c|}{ Year of first exposure } \\
\hline & $\begin{array}{l}\text { Prior to } 1963 \\
\text { SMR (OBS) }\end{array}$ & $\begin{array}{l}1963-70 \\
\text { SMR (OBS) }\end{array}$ & $\begin{array}{l}1971 \text { or later } \\
\text { SMR (OBS) }\end{array}$ \\
\hline $\begin{array}{l}\text { All deaths } \\
\text { All cancers (140-208) } \\
\text { Trachea, bronchus, and lung CA (162) } \\
\text { Prostate CA (185) } \\
\text { Brain CA }(191,192) \\
\text { Connective and soft tissue CA (171) } \\
\text { Leukaemia (204-208) } \\
\text { Myeloid leukaemia (205) } \\
\quad \text { Acute myeloid leukaemia (205.0) } \\
\text { Heart disease (390-398, 402,404,410-414, 420-429) } \\
\text { Ischaemic heart disease (410-414) } \\
\text { Cardiomyopathy, conductive disorders, and other heart } \\
\text { diseases (420-423, 425-428, 429.2, 429.9) }\end{array}$ & $\begin{array}{l}0.91(1543)^{* *} \\
0.86(412)^{\star *} \\
0.86(89) \\
1.32(5) \\
1.17(14) \\
1.10(3) \\
1.23(19) \\
1.61(11) \\
1.81(8) \\
0.93(516) \\
0.90(357)^{*} \\
1.18(128)\end{array}$ & $\begin{array}{l}0.97(494) \\
0.94(142) \\
1.06(39) \\
1.64(4) \\
0.97(4) \\
2.47(3) \\
0.81(4) \\
1.15(3) \\
-(0) \\
1.04(131) \\
1.05(88) \\
1.24(37)\end{array}$ & $\begin{array}{l}0.88(169) \\
1.11(54) \\
1.83(19) \text { * } \\
2.80(2) \\
0.76(1) \\
1.95(1) \\
0.56(1) \\
1.02(1) \\
1.60(1) \\
1.14(45) \\
1.40(33) \\
0.88(10)\end{array}$ \\
\hline \multicolumn{4}{|c|}{$\begin{array}{l}\text { OBS, observed number of deaths, SMR, standardised mortality ratio, CA, cancer. } \\
\text { †Results for myeloid leukaemia and acute myeloid leukaemia are for } 1960 \text { and } 1968 \text {, respectively, when US population rates for myeloid leukaemia and acute } \\
\text { myeloid leukaemia were first available, through } 1998 \text {. } \\
\text { †Results for all race/sex groups combined. } \\
\text { §International Classification of Diseases, 9th revision. } \\
* 95 \% \mathrm{Cl} \text { excludes the null value (1.0). } \\
* * 99 \% \mathrm{Cl} \text { excludes the null value (1.0). }\end{array}$} \\
\hline
\end{tabular}


leukaemia in adults, is over $70 \% .{ }^{15}$ This suggests that mortality, especially underlying cause mortality, may not be a sensitive outcome measure for lymphocytic leukaemia. Myeloid leukaemia mortality was highest among workers with 10 or more years of exposure, among workers with 20 or more years since first exposure, and among workers who were first exposed prior to 1963 when exposures were presumably higher, which is consistent with the hypothesis that the observed excess in myeloid leukaemia mortality is related to formaldehyde exposure. Because formaldehyde is water soluble, highly reactive, and rapidly metabolised, carcinogenic effects at sites distant from the portal of entry are considered less likely than carcinogenic effects at the sites of direct contact. ${ }^{16}{ }^{17}$ However, transport of formaldehyde to distant sites and subsequent carcinogenic effects cannot be excluded. Our finding of an excess in leukaemia mortality is consistent with several studies of formaldehyde exposed professional groups. ${ }^{6}$ In contrast, mortality from leukaemia was not increased among 26561 workers employed at 10 US formaldehyde producing or using plants, ${ }^{18}$ or among 14037 men employed at six British formaldehyde producing or using plants. ${ }^{19}$ Both of these studies included workers who were exposed to much higher levels of formaldehyde $(>2 \mathrm{ppm})$ than those measured at the plants in this study in the 1980s. Workers in our study were probably exposed to higher concentrations of formaldehyde in earlier years than in the 1980s, but the level of exposure is unknown. Investigators also found no evidence for an increased risk of leukaemia among US automotive iron foundry workers exposed to formaldehyde ${ }^{20}$ or among men in the Danish Cancer Registry who had their longest work experience at a formaldehyde using or producing company. ${ }^{21}$ Wong reported an excess in leukaemia among a small cohort, ${ }^{22}$ but the observed excess was based on only two observed deaths and the study plant was included in the large US study ${ }^{18}$ of formaldehyde using or producing facilities in which no excess in leukaemia mortality was found. ${ }^{6}$ Most previous studies of formaldehyde exposed workers have not evaluated cell type specific leukaemia mortality. However, the observed excess in myeloid leukaemia mortality is consistent with studies of formaldehyde exposed professional groups in which the risk of cell type specific leukaemia mortality was evaluated. ${ }^{23-26}$

Several reasons have been postulated for the observed risk of leukaemia among formaldehyde exposed professional groups versus industrial cohorts, including the possibility that the increased risk of leukaemia mortality observed in professional groups is due to occupational exposures other than formaldehyde. ${ }^{6}$ Diagnostic bias has also been suggested as a possible explanation since professional groups may receive better medical care than the general population. ${ }^{6}$ Neither of these possibilities are likely explanations for the findings in this study. Industrial hygiene surveys conducted at the time of the original study did not identify any chemical exposures at the study plants other than formaldehyde which were likely to influence the study findings. ${ }^{1}$ Diagnostic bias is also less likely in this study of garment workers than in studies of medical professionals such as pathologists. Internal analyses were conducted for mortality from leukaemia to address the potential problems associated with using the US general population as the reference population and comparing SMRs across subgroups of the cohort. Similar patterns of risk were observed across exposure duration categories in the internal analyses. However, we could only crudely adjust for age in the internal analysis, because of the limited number of observed deaths.

There is little evidence for an increased risk of mortality from respiratory cancers in this update. Although the original study reported an excess in mortality for both lung and pharyngeal cancer, we did not observe an excess in mortality from either of these cancers among the entire cohort. Lung cancer mortality was increased among workers first exposed during the most recent years when exposures to formaldehyde were the lowest. Lung cancer mortality was also increased among workers with the shortest duration of exposure and time since first exposure. These findings suggest that the excess in lung cancer mortality observed among some groups of workers in this cohort is due to factors other than formaldehyde exposure. Some investigators have concluded that formaldehyde exposure is most likely to cause nasopharyngeal and nasal cancers. ${ }^{5-7}$ No nasal or nasopharyngeal cancers were observed in this study.

Cancers of the buccal cavity are also biologically plausible since direct contact with formaldehyde may occur in the buccal cavity. There were no additional deaths from buccal cancer, based on underlying cause of death, observed in this update. The excess risk of mortality from buccal cancer that was noted in the original study decreased considerably from an SMR of 3.43 to an SMR of 1.33. Buccal cancer mortality was not increased in previous meta-analyses of the carcinogenic effects of formaldehyde. ${ }^{67}$

Mortality from cardiomyopathy, conductive disorders, and other heart disease was increased based on US population mortality rates. There is no known association between inhalational exposure to formaldehyde and heart disease. ${ }^{16}$ The results from the analysis using state rates suggest that the finding may be related to regional differences. Mortality from cardiomyopathy, conductive disorders, and other heart diseases was also highest among workers with less than three years of exposure, suggesting that this finding is not related to formaldehyde exposure.

This study had limited power, despite the large cohort size, to detect an excess in mortality from some of the cancers of a priori interest. The power of this study to detect a twofold or greater increase in mortality from nasopharyngeal cancer and from nasal cancer was only $13 \%$ and $16 \%$, respectively. In addition, exposure-response relations could only be evaluated using duration of exposure. This may have introduced some misclassification and biased the exposure-response relation towards the null since exposures probably decreased substantially over time as improvements were made in the resin systems used to treat fabrics. Other limitations include the relatively low levels of formaldehyde since at least 1981 to which workers in this study were exposed, the lack of data on formaldehyde levels prior to 1981, the lack of data on other risk factors for cancers of interest, and the reliance on mortality data only. Although the work history records for this study were obtained in the early 1980s and were not updated, the sensitivity analysis suggests that the impact of not updating the work histories is minimal. Strengths of the current study include the large cohort size, the inclusion of many women, the lack of other occupational exposures at the study plants that are likely to have influenced the study findings, the long period of follow up, and the evaluation of multiple cause mortality in addition to underlying cause mortality.

In summary, the results, although not conclusive, support a possible relation between formaldehyde exposure and myeloid leukaemia mortality. The findings for leukaemia mortality are consistent with the findings of several studies of professional groups exposed to formaldehyde, but are in contrast to other large studies of formaldehyde exposed industrial workers. We found no evidence of an association between formaldehyde exposure and mortality from respiratory cancers. An increased risk of mortality from buccal cancer, based on four observed cancers, was observed, but the results from this update are far weaker than those from the previous study and not supported by other epidemiologic studies. Non-significant excesses in mortality were observed 
for several other cancers, but there was no clear relation between the observed excesses and duration of exposure. Limitations of the study include limited power to detect an excess in mortality from rare cancers and lack of individual exposure estimates.

\section{Authors' affiliations}

L E Pinkerton, M J Hein, Industrywide Studies Branch, Division of Surveillance, Hazard Evaluations and Field Studies, The National Institute for Occupational Safety and Health, Cincinnati, Ohio, USA L T Stayner, Risk Evaluation Branch, Education and Information Division, The National Institute for Occupational Safety and Health, Cincinnati, Ohio, USA

The manuscript was written by employees of the US government as part of their official duties; the work is therefore not subject to copyright.

\section{REFERENCES}

1 Stayner LT, Elliott L, Blade L, et al. A retrospective cohort mortality study of workers exposed to formaldehyde in the garment industry. Am J Ind Med 1988; 13:667-81

2 Stayner L, Smith AB, Reeve G, et al. Proportionate mortality study of workers in the garment industry exposed to formaldehyde. Am J Ind Med 1985:7:229-40.

3 Albert RE, Sellakumar AR, Lasin S, et al. Gaseous formaldehyde and hydrogen chloride induction of nasal cancer in the rat. J Natl Cancer Inst 1982;68:597-603.

4 Swenberg JA, Kerns WD, Mitchell RI, et al. Induction of squamous cell carcinomas of the rat nasal cavity by inhalation exposure to formaldehyde vapor. Cancer Res 1980;40:3398-402.

5 International Agency for Research on Cancer. IARC monographs on the evaluation of carcinogenic risks to humans. Vol. 62. Wood dust and formaldehyde. Lyon, France: IARC, 1995.

6 Blair A, Saracci R, Stewart PA, et al. Epidemiologic evidence on the relationship between formaldehyde exposure and cancer. Scand J Work Environ Health 1990;16:381-93.

7 Partanen T. Formaldehyde exposure and respiratory cancer-a meta-analysis of the epidemiologic evidence. Scand J Work Environ Health 1993;19:8-15.

8 Collins JJ, Acquavella JF, Esmen NA. An updated meta-analysis of formaldehyde exposure and upper respiratory tract cancers. J Occup Environ Med 1997;39:639-51.

9 Elliott LJ, Stayner LT, Blade LM, et al. Formaldehyde exposure characterization in garment manufacturing plants: a composite summary of three in-depth industrial hygiene surveys. Cincinnati, $\mathrm{OH}$ : Division of Surveillance, Hazard Evaluations and Field Studies, National Institute for Occupational Safety and Health, 1987.

10 Waxweiler RJ, Beaumont JJ, Henry JA, et al. A modified life table analysis system for cohort studies. J Occup Med 1983;25:115-24.

11 Steenland K, Beaumont J, Spaeth S, et al. New developments in the life table analysis system of the National Institute for Occupational Safety and Health. J Occup Med 1990;32:1091-8.

12 Steenland K, Spaeth S, Cassinelli R II, et al. NIOSH life table program for personal computers. Am J Ind Med 1998;34:517-18.

13 Steenland K, Nowlin S, Ryan B, et al. Use of multiple-cause mortality data in epidemiologic analyses: US rate and proportion files developed by the National Institute for Occupational Safety and Health and the National Cancer Institute. Am J Epidemiol 1992;136:855-62.

14 Breslow NE, Day NE. Comparisons among exposure groups. In: Heseltine $\mathrm{E}$, ed. Statistical methods in cancer research. Volume II: The design and analysis of cohort studies. IARC (International Agency for Research on Cancer) Scientific Publication No. 82. New York: Oxford University Press, 1987:69.

15 Ries LAG, Eisner MP, Kosary CL, et al, eds. SEER cancer statistics review, 1975-2000, National Cancer Institute. Bethesda, MD, http:// seer.cancer.gov/csr/1975_2000, 2003.

16 ATSDR. Toxicological profile for formaldehyde. Atlanta, GA: US Department of Health and Human Services, Public Health Service, 1999.

17 Medinsky MA, Bond JA. Sites and mechanisms for uptake of gases and vapors in the respiratory tract. Toxicology 2001;160:165-72.

18 Blair A, Stewart $P, O^{\prime}$ Berg $M$, et al. Mortality among industrial workers exposed to formaldehyde. J Natl Cancer Inst 1986;76:1071-84.

19 Gardner MJ, Pannett B, Winter PD, et al. A cohort study of workers exposed to formaldehyde in the British chemical industry: an update. $\mathrm{Br} J$ Ind Med 1993;50:827-34.

20 Andjelkovich DA, Janszen DB, Brown MH, et al. Mortality of iron foundry workers: IV. analysis of a subcohort exposed to formaldehyde. J Occup Environ Med 1995;37:826-37.

21 Hansen J, Olsen JH. Formaldehyde and cancer morbidity among male employees in Denmark. Cancer Causes Control 1995;6:354-60.

22 Wong $\mathrm{O}$. An epidemiologic mortality study of a cohort of chemical workers potentially exposed to formaldehyde with a discussion on SMR and PMR. In: Gibson JE, ed. Formaldehyde toxicity. New York: Hemisphere Publishing Co., 1983:256-72.

23 Walrath J, Fraumeni JF Jr. Mortality patterns among embalmers. Int J Cancer 1983;31:407-11.

24 Walrath J, Fraumeni JF Jr. Cancer and other causes of death among embalmers. Cancer Res 44:4638-41.

25 Stroup NE, Blair A, Erickson GE. Brain cancer and other causes of death in anatomists. J Natl Cancer Inst 1986;77:1217-24.

26 Hayes RB, Blair A, Stewart PA, et al. Mortality of U.S. embalmers and funeral directors. Am J Ind Med 1990;18:641-52. 